3. Noble MJ, Smith JR, Windley J. A controlled retrospective pilot study of an at-risk asthma register in primary care. Prim Care Respir J 2006;15:116-124

http://dx.doi.org/10.1016/ j.pcrj.2006.01.002

4. Harrison BDW, Slack R, Berrill WT, Burr ML, Stableforth DE, Wright SC. Results of a national confidential enquiry into asthma deaths. Asthma J 2000;5:180-6.

5. Anagostou K, Harrison BDW, lles R, Nasser S. Risk factors for childhood asthma deaths from the UK Eastern Region Confidential Enquiry 2001-2006. Prim Care Respir J 2012;21(1):71-7. http://dx.doi.org/10.4104/pcrj.2011.00097

6. British Guideline on the Management of Asthma. A national clinical guideline. Thorax 2008;63(Suppl IV);iv1-iv121. http://dx.doi.org/10.1136/thx.2008.097741

(C) 2012 Primary Care Respiratory Society UK. All rights reserved.

http://dx.doi.org/10.4104/pcrj.2012.00033

\section{Conflicting standards for diagnostic spirometry within-session repeatability are confusing}

Dear Sirs,

Following the publication in this journal of the Standards document 'Diagnostic Spirometry in Primary care: Proposed standards for general practice compliant with American Thoracic Society and European Respiratory Society recommendations' by Levy et al. in September 2009, ${ }^{1}$ Fletcher \& Loveridge ${ }^{2}$ from Education for Health felt compelled to challenge the 'soft' limit of $150 \mathrm{ml}$ for within-session repeatability included in the document and stated that this should be reduced to $100 \mathrm{ml}$. There was further discussion ${ }^{3}$ around this point, and the assumption was made that further research would provide clarification.

Two years on, guidelines and international primary care resources continue to offer conflicting advice as to whether $100 \mathrm{ml}$ or $150 \mathrm{ml}$ should be the standard for within-session repeatability, and there still appears to be a lack of research in this area.

At the time of Fletcher and Loveridge's original letter, ${ }^{2}$ Education for Health undertook an audit of the within-test repeatability of spirometries within the portfolios of 10 recently successful students. These all demonstrated within-test repeatability of between $30-70 \mathrm{ml}$ in real patients with respiratory disease.

All Education for Heath spirometry students are assessed (and indeed pass or fail) on the Association for Respiratory Technology and Physiology (ARTP) $100 \mathrm{ml}$ standard, ${ }^{4}$ with the majority achieving lower than $100 \mathrm{ml}$ within-session repeatability in three to four relaxed and forced blows. Respiratory Education UK and the ARTP also assess their own students to this standard, and - as outlined in Brendan Cooper's later PCRJ response ${ }^{5}$ - all physiologists are expected to achieve this.

Interestingly, the recently published GOLD guidelines (GOLD 2011) ${ }^{6}$ have reverted from $150 \mathrm{ml}$ to a lower limit of $100 \mathrm{ml}$ or $5 \%$, whichever is greater.

In contrast, however, the PCRS-UK has adhered to $150 \mathrm{ml}$ as the standard for within-session repeatability in all its materials and advice, including its spirometry audit, in line with the 2009 PCRJ publication. ${ }^{1}$ As members of the PCRS-UK Education Committee, we are increasingly concerned that conflicting standards are confusing for primary care health professionals. We look forward to further debate on this issue, and also respectfully request the authors of the original paper to provide further clarification on this issue.

*Kevin Gruffydd-Jonesa, Hilary Pinnock ${ }^{\mathrm{b}}$, Chris Loveridgec, Stephanie Wolfe ${ }^{d}$, Ruth McArthurc, David Bellamye

a Box Surgery, Box, Wiltshire, UK

b Allergy and Respiratory Research Group, University of Edinburgh, UK

c Education for Health, Warwick, UK

d Primary Research Ltd, Norwich UK

e PCRS-UK COPD Editor, UK

*Correspondence: gruffbox@btinternet.com

Received 24th April 2012; accepted 3rd May 2012; online 23rd May 2012

Conflicts of interest $\mathrm{CL}, \mathrm{RMC}$ and $\mathrm{SW}$ are employees of Education for Health. HP and $\mathrm{DB}$ are Associate Editors of the PCRJ; neither were involved in the editorial review of, nor the decision to publish, this article.

\section{References}

1. Levy ML, Quanjer PH, Booker R, Cooper BG, Holmes S, Small I. Diagnostic Spirometry in Primary Care: Proposed standards for general practice compliant with American Thoracic Society and European Respiratory Society recommendations. Prim Care Respir J 2009;18(3):130-47. http://dx.doi.org/10.4104/pcrj.2009.00054

2. Fletcher $M$, Loveridge $C$. Recommendations on repeatability of spirometry. Prim Care Respir J 2010;19(2):192-3. ttp://dx.doi.org/10.4104/pcrj.2010.00026

3. Enright P. FEV1 and FVC repeatability goals when performing spirometry. Prim Care Respir J 2010;19(2):194. http://dx.doi.org/10.4104/pcrj.2010.00031

4. British Thoracic Society and Association for Respiratory Technology and Physiology. Guidelines for the measurement of respiratory function. Resp Med 1994;88:165-94

5. Cooper B. Spirometry standards and FEV1/FVC repeatability. Prim Care Respir J 2010;19(3):292-4. http://dx.doi.org/10.4104/pcrj.2010.00050

6. GOLD 2011 guidelines. www.goldcopd.org/guidelines-global-strategy-for-diagnosismanagement.html.

(C) 2012 Primary Care Respiratory Society UK. All rights reserved.

http://dx.doi.org/10.4104/pcrj.2012.00044

\section{Why do patients not attend community- based pulmonary rehabilitation, and how can attendance be improved?}

Dear Sirs,

We read with great interest the paper by Zakrisson et al. ${ }^{1}$ in the December 2011 issue of the PCRJ. We thank and congratulate the authors for their interesting work.

Of particular interest to us is the issue of patients not attending a pulmonary rehabilitation (PR) programme and the reasons behind this. NICE guidelines for $\mathrm{COPD}^{2}$ recommend pulmonary rehabilitation for all patients who are functionally disabled due to their disease. In Zackrisson's study, out of 83 patients allocated to the PR intervention group, $56.6 \%$ completed the full programme, $2.4 \%$ dropped out before the end, and $41 \%$ declined to participate altogether. ${ }^{1}$ The reasons for not attending at all or leaving the programme before its completion were; patients leaving town $(5.6 \%)$; their condition being bad $(2.2 \%)$; they would not participate in groups $(8.3 \%)$; and the time of the sessions being unsuitable $(2.8 \%)$. The biggest group was where the reason was described as "other". Full details of the reasons in this group were not specified.

In the semirural county of Somerset, UK, PR is provided in community-based centres. Patients are referred from primary as well as secondary care, and the PR programme runs for a period of six weeks. Attendance in this programme was poor, but the reasons for this had not previously been investigated. We therefore carried out a 
retrospective postal survey to investigate the extent of, and the reasons for, non-attendance at the PR programme, with the aim of making recommendations to improve future attendance. Our results are notably different to those obtained by Zakrisson et al.

We sent out questionnaires to 88 patients who had previously been invited to the PR programme. Out of the 48 responded, the response rate was $54.5 \%$. Only $13 \%$ had completed the full PR programme, $34 \%$ dropped out before the end, and $53 \%$ did not participate at all.

$21 \%$ of responders indicated that they had not received notification of the appointment. Amongst those who did receive the appointment, the top three reasons for not attending either in part or altogether were health-related reasons $(37.5 \%)$, personal and social reasons $(34.3 \%)$, and because patients did not think that PR would help them $(31.2 \%)$. Other reasons were: inconvenient location $(15.6 \%)$; lack of transport $(9.3 \%)$; lack of enough information $(3.1 \%)$; and not enough notice $(3.1 \%)$. Only a minority of patients $(21.8 \%)$ who failed to attend either part or the whole of the programme were sent a second appointment. The rest $(88 \%)$ of this group indicated that they would not have attended even if they had been sent another appointment. Of those who indicated that they did not attend because the venue was inconvenient, $63.3 \%$ said they would not have attended even if they were offered a venue nearer to their home.

Although it might be difficult to influence patients' personal, healthand social-related issues in this context, telephone confirmation of the appointment beforehand, with explanation of the benefits of PR, the offer of transport, sufficient advance notice and a convenient venue, may help to improve attendance at the PR programme. Although these results were obtained from a specific geographical area, these general reasons for non-attendance at a PR programme are likely to be similar elsewhere. Not attending a PR programme deprives patients of the benefits of this extremely effective modality in the management of their COPD.

\footnotetext{
*Rajendra Kumar Sinhaa, Charlotte Mitchell ${ }^{\mathrm{b}}$

a Consultant Respiratory Physician, Yeovil District Hospital, Yeovil, Somerset, UK.

b Senior Clinical Governance Assistant, Yeovil District Hospital, Yeovil, Somerset, UK
}

*Correspondence: rajendra.sinha@ydh.nhs.uk

Received 24th April 2012; accepted 3rd May 2012; online 23rd May 2012

Acknowledgements We thank Somerset Community COPD Services for supplying the names of patients for this survey.

Conflicts of interest The authors declare that they have no conflicts of interest in relation to this article.

Funding No funding was received for this survey

\section{References}

1. Zakrisson A-B, Engfeldt $P$, Hagglund $D$ et al. Nurse-led multidisciplinary programme for patients with COPD in primary health care: a controlled trial" Prim Care Respir J 2011; 20(4):427-33. http://dx.doi.org/10.4104/pcrj.2011.00060

2. Management of chronic obstructive pulmonary disease in adults in primary and secondary care. National Institute for Health and Clinical Excellence - clinical guideline 101, June 2010

(C) 2012 Primary Care Respiratory Society UK. All rights reserved.

http://dx.doi.org/10.4104/pcrj.2012.00042

\section{The implementation of a COPD continuous management improvement programme: learning for the future}

Dear Sirs,

Adherence to recommended standards of management (such as NICE guidelines in the UK) differs widely in clinical practice. Programmes of management appear to drive improved patient outcomes, and there have been several reports in this journal recently of the benefits that follow formalised COPD disease management programmes. ${ }^{1-3}$ In the most recent paper by Zakrission et al. in the December 2011 issue, ${ }^{3}$ there was a significant reduction in exacerbation frequency in those patients in the intervention group.

We therefore wish to report the findings of an audit and targeted education programme on the management of COPD patients in Dartford, Gravesham and Swanley (DG\&S) in West Kent, UK, focussed on the 2004 UK COPD NICE guidelines. ${ }^{4}$ A proprietary general practice data audit tool (POINTS) (identical to the tool used by Roberts et al. ${ }^{2}$ previously) was integrated into 30 practices, and data were collected from patients on the COPD registers. An education programme was incorporated to underpin the launch and implementation of the programme, and there were additional COPD clinic hours provided. The programme also incorporated qualitative interviews with practice members to determine attitudes and to learn from the process.

The programme was succesful in improving the management of COPD patients in DG\&S according to NICE guidelines over a 12-month period. Key improvements included statistically significant improvements to the categorisation of patients by COPD severity ( $42 \%$ up to $60 \%$; $\mathrm{p}<0.001$ ) and the recording of patient-centric measures (FVC, exacerbations, and MRC dyspnoea scores; $p<0.001$. Inhaler technique measurement; $p<0.01$ ).

The level of participation in the education programme and the number of additional clinic hours appeared to drive improved interest, knowledge and care of patients with COPD. Practices involved in less than 25 hours education and additional clinic hours had significantly more patients categorised to severity at baseline than those undertaking $25-49$ and $\geq 50$ hours education and additional clinic hours $(p<0.001)$. At 12 months, how ever, there were no significant differences between the level of categorisation between the three groups. These improvements were validated by the qualitative analysis which showed that highly engaged practices accepted, implemented and valued the programme and saw the advantage of the better patient care it created.

Even in its infancy, the impact of the programme of audit and targeted education is impressive; the rate of increase in unscheduled hospital admissions for the year following the programme in the DG\&S locality was $2 \%$, compared to $55 \%$ in the remainder of the Primary Care Trust, and $12 \%$ in England - a trend replicated in the cost of admissions data.

A central feature in the success of this programme was the use of the POINTS audit tool which served two important purposes. It provided a patient-linked reminder of the key elements of NICE guidance at each consultation, and it provided detailed data on the COPD patient population in primary care. POINTS provided reliable data on current management practices which facilitated the identification of gaps in service provision and unmet patient needs and allowed targeted training programmes to be undertaken. This would not be feasible without such 